Preference is given to letters commenting on contributions published recently in the JRSM. They should not exceed 300 words and should be typed double spaced

\section{Pregnancy and coarctation of the aorta}

Discussing the management of coarctation of the aorta in pregnancy, Dr Venning and her colleagues (May 2003 $J R S M^{1}$ ) emphasize the importance of close monitoring, control of hypertension and a multidisciplinary approach. We agree absolutely; but we disagree with their recommendation that 'elective caesarean section be performed in such cases to avoid the second stage and to reduce the need for Valsalva manoeuvres . . .'

We have cared jointly for many parturients with cardiac disease, including coarctation and Marfan's syndrome, and unless the mother or fetus is in imminent danger we recommend vaginal delivery with low-dose epidural analgesia, and elective instrumental delivery without maternal pushing in the second stage, to avoid Valsalva manoeuvres. This avoids the risks associated with caesarean section-namely, bleeding, deep vein thrombosis, infection, the need for intravenous Syntocinon (oxytocin) with its potential for adverse cardiovascular effects, and an increased requirement for caesarean section in subsequent pregnancies. Furthermore, both regional anaesthesia (which we prefer) and general anaesthesia for caesarean section are more likely to induce cardiovascular instability than low-dose epidural analgesia in labour. If caesarean section is required, the epidural can be readily extended in most cases.

In the past, elective caesarean section (usually under general anaesthesia) was the mode of delivery for many women with cardiac disease, but there is increasing evidence that vaginal delivery with regional analgesia can produce a good outcome. ${ }^{2}$ Elective caesarean section may be desirable in the occasional patient with coarctation and uncontrollable systemic hypertension, marked aortic root dilatation and/or severe residual or native coarctation, ${ }^{3}$ although supportive data for this approach are clearly required.

\section{Steve Yentis $^{1}$}

\section{Michael A Gatzoulis ${ }^{2}$}

\section{Philip Steer ${ }^{3}$}

${ }^{1}$ Department of Anaesthesia, Chelsea \& Westminster Hospital, London SW10 9NH; ${ }^{2}$ Adult Congenital Heart Programme, Royal Brompton Hospital, London SW3 6NP ${ }^{3}$ Academic Department of Obstetrics, Imperial College, Chelsea \& Westminster Hospital, London SW7 2AZ, UK

\section{REFERENCES}

1 Venning S, Freeman LJ, Stanley K. Two cases of pregnancy with coarctation of the aorta. J R Soc Med 2003;96:234-6

2 Dob DP, Yentis SM. UK Registry of High-risk Obstetric Anaesthesia: report on cardiorespiratory disease. Int J Obstet Anesth 2001;10:267-72

3 Beauchesne LM, Connolly HM, Ammash NM, Warnes CA. Coarctation of the aorta: outcome of pregnancy. J Am Coll Cardiol 2001;38:1728-33

\section{Sylvia Plath and the depression continuum}

The use made by Dr Cooper (June 2003 JRSM $M^{1}$ ) of Sylvia Plath's case history to explore psychiatric nosology is interesting and his conclusion that she suffered from borderline personality disorder (BPD) is convincing. But there are further diagnostic issues to be considered. I have argued elsewhere ${ }^{2}$ that reliance on the DSM list of traits to diagnose BPD fails to highlight a central characteristic of these patients, namely a form of instability which reflects the alternating operation of one or other of a small range of patterns of interpersonal and intrapersonal functioning. This fragmented structure is initiated, in those genetically prone, by childhood exposure to psychologically unmanageable experiences. Subsequently, perceptions, experiences or thoughts of rejection or of threat can activate this dissociation. A relatively small range of constituent states is met with in borderline patients ${ }^{3}$ and these are most usefully described in terms of the relationship patterns determining interpersonal perceptions and behaviour and self attitudes and management. The 'overresponsiveness to daily experiences' and 'heightened reactivity to life's upsand-downs' which Plath and other borderline people manifest are more accurately described by this 'multiple self states model' (MSSM). Four commonly encountered borderline states are evident in the case of Plath. The first is a state found in all borderline patients in which relationships are of the form 'abusing/abandoning to abused/abandoned'. Plath was over reactive to hints of rejection and could herself switch suddenly from closeness to abusing and rejecting others and harming herself. Second, striving can lead to real success, as with Plath, and praise can compensate for feeling unloved. But any hint of criticism or rejection can provoke catastrophic reactions, representing a switch from the 'striving-praising' to the 'abusingabused' pattern, as evident in her self-harm and attempted suicide at Harvard. Third, intense relationships with idealized others can support phases of wellbeing and creativity but the actual or perceived shortcomings or betrayals of the other provoke switches into abusive patterns; this was manifest in her violently oscillating relationship with Hughes, well described in his Birthday Letters. Fourth, Plath's poetry can be seen to be preoccupied with 'borderline' themes (loss, violence and contradictory experiences of the self) but these do not necessarily generate poetry. The association of instability with creativity is probably linked with another borderline trait, the capacity for intense concentration. This represents a dissociation from current surroundings and preoccupations, even when these are difficult, as they were while she was writing Ariel.

The distinction between bipolar disorders and borderline states may be less clear than Cooper suggests. Borderline states vary in the frequency with which they are mobilized and 
in their duration, and what provokes switches may not be apparent. The contrasting moods of bipolar patients are accompanied by changes in self-management and relationship patterns and their state switches may be reactive to life events. Borderline patients may be helped by mood stabilizing drugs and bipolar patients may be helped by psychotherapy. ${ }^{4}$ I would suggest that, in comparing the two conditions, the model of BPD needs to incorporate the structural understandings of the MSSM.

\section{Anthony Ryle}

3 Goulton Road, London E58HA, UK

E-mail: rylecat@aol.com

\section{REFERENCES}

1 Cooper B. Sylvia Plath and the depression continuum. J R Soc Med 2003;96:296-301

2 Ryle A. Cognitive Analytic Therapy and Borderline Personality Disorder. Chichester: Wiley, 1997

3 Golynkina K, Ryle A. The identification and characteristics of the partially dissociated states of patients with borderline personality disorder. BrJ Med Psychol 1999;72:429-45

4 Kerr IB. Brief cognitive analytic therapy for post-acute manic psychosis on a psychiatric intensive care unit. Clin Psychol Psychother 2001;8: $117-29$

\section{Cocaine by internal mail}

I welcome the comments of Mr Bycroft (June 2003 JRSM $M^{1}$ ) on the odious use of children as surgical mules, but take issue with his statement about the occasional radiolucency of intracorporal drug packages.

Our statement that ingested narcotic containing packages are invariably radio-opaque ${ }^{2}$ was based on empirical experience from the Hillingdon Hospital (which takes the majority of symptomatic surgical mules apprehended at Heathrow Airport). In the past three years we have not seen a single patient whose concealed packages were not radio-opaque. The evidence cited by Mr Bycroft is well over a decade old. International drug trafficking has evolved considerably since then. The surgical mule is recruited by highly organized cartels that target vulnerable populations in some of the world's most impoverished regions. The packages usually contain cocaine (approximately $10 \mathrm{~g}$ ) and are invariably factory processed: the narcotic powder is highly compressed and then encased in a protective cellophane coat. Their characteristic shape and density makes them readily visible radiologically - even with a faecally loaded colon.

Our experience is supported by that of Bulstrode and colleagues, who reported a series of 180 surgical mules, all identified by a plain abdominal radiograph. ${ }^{3}$ Jones and Shorey presented 51 mules who were similarly diagnosed. ${ }^{4}$ A Dutch group concluded that, of 40 consecutive 'body- identifiable packages on plain abdominal X-ray. ${ }^{5}$ With a lack of contemporaneous evidence to the contrary, we agree with Krishnan and Brown, that plain abdominal radiography is a key diagnostic tool in this patient group. ${ }^{6}$

If recreational drug users knew the enteric history of much of the cocaine available on British streets, would they be so keen to use it?

\section{Marc C Swan}

Department of Plastic \& Reconstructive Surgery, Radcliffe Infirmary, Oxford OX2 6HE, UK

\section{REFERENCES}

1 Bycroft B. Cocaine by internal mail. J R Soc Med 2003;96:315

2 Swan MC, Byrom R, Nicolaou M, Paes T. Cocaine by internal mail: two surgical cases. $J$ R Soc Med 2003;96:188-9

3 Bulstrode N, Banks F, Shrotria S. The outcome of drug smuggling by 'body packers' - the British experience. Ann $R$ Coll Surg Engl 2002;84:35-8

4 Jones OM, Shorey BA. Body packers: grading of risk as a guide to management and intervention. Ann R Coll Surg Engl 2002;84:131-2

5 Van Geloven AA, Van Lienden KP, Gouma DJ. Bodypacking-an increasing problem in The Netherlands: conservative or surgical treatment? Eur J Surg 2002;168:404-9

6 Krishnan A, Brown R. Plain abdominal radiography in the diagnosis of the "'body packer'. J Accid Emerg Med 1999;16:381

\section{Legal considerations of clinical guidelines}

The comprehensive paper by Dr Samanta and colleagues (March $2003 J R S M^{1}$ ) indicates that NICE guidelines may require greater authority in the courts in clinical negligence cases in the future. This may well be a correct analysis of the situation, but should it be so? Guidelines can only ever be just what they are called, since medical knowledge and practice is constantly changing. Therefore, guidelines can never be fully up to date. For example, a guideline about hormone replacement therapy twelve months ago would have stressed the value of this treatment for prevention of heart disease. Theoretically, at that time a menopausal woman not so protected who suffered a heart attack would have a case of negligence to claim. One year later, a woman so treated who developed breast cancer might claim that she had not been adequately made aware of the risks of cancer, newly understood.

The development of NICE guidelines seems to reflect dissatisfaction about medical practice in the UK. This is now hampered by at least two serious problems outside of the profession's control. These are, first, the nature of the National Health Service-a monolithic and grossly inefficient government-controlled bureaucracy that is working senior doctors to breaking point and has since its inception replaced the contract between doctor and patient. Until the personal contract is restored, patients will have little choice and will continue to receive less than ideal service. 
Medicine is an art as well as a science, and the trust between the physician/healer and the patient is often an important part of therapy. Each case is a sample of one, however commonplace the condition. A standard guideline of treatment for, say, thyrotoxicosis might be totally wrong, even dangerous, for a patient with preexisting heart disease suspected or known. This situation requires a specialist physician with greater than average knowledge and above all experience and ability to consult colleagues, and cannot be reduced to a formula. Guidelines are useful distillations of published data and expert opinion, but they must not replace the factors of judgment and experience that years in medical practice bring, or their use deemed as critical evidence in a court of law. From personal experience I assure the reader that, when one is seriously ill, what is required is a competent, experienced and reliable doctor, not a technician with guidelines.

The NICE guideline on pressure ulcer risk assessment and prevention, April 2001, is very much the province of both nurse and doctor. These guidelines are a detailed counsel of perfection, presuming the availability of ideal nursing care. Which leads to the second point: to be safe and effective, doctors need the support and trust of nurses. In the hospital service this is not always available. In addition to deficiencies in nursing support, there is a growing tendency for paramedical specialists of all disciplines (physiotherapists, occupational therapists, etc.) to operate independently of the medical profession, resulting in confusion and error for the patient and trouble for the doctor. Clearly a high standard of nursing and directed teamwork is vital to patient wellbeing and safety. Since it is the doctor who shoulders most responsibility, he or she must remain in charge of the patient.

It is worrying for the medical profession that lawyers are increasingly, whether intentionally or not, seeking to dictate the practice of medicine.

\section{R J Walden}

Bossall, 126 Bluehouse Lane, Limpsfield, Surrey RH8 OAR, UK E-mail richard@walden60.fsnet.co.uk

\section{REFERENCE}

1 Samanta A, Samanta J, Gunn M. Legal considerations of clinical guidelines: will NICE make a difference? J R Soc Med 2003;96:133-8

\section{Treatment options for snoring}

Having read the article by Mr Kotecha and Dr Shneerson (July $2003 J^{2} S M^{1}$ ) I should like to draw attention to another possible option for the treatment of snoring which does not involve surgery. It is not widely known that hypnotherapy can be a useful tool for eliminating snoring. Until quite recently the focus of attention in hypnotherapy has been to reduce alcohol intake, and also to ensure weight reduction. However, in a recent study, ${ }^{2}$ direct suggestion under hypnosis was used so that the patient would immediately turn on his side when snoring at night. This led to a reduction in the intensity and duration of the snoring response. The patient was encouraged to learn self-hypnosis and was instructed to carry this out daily. At first, he was somewhat reluctant to do this, but as the treatment progressed and he could see the effectiveness of the technique-his wife volunteered that both the volume and the duration of the snoring had improved - he became more enthusiastic. Later, he could see that a reduction of alcohol intake and weight loss were important and, by the end of the treatment, he had lost $6 \mathrm{~kg}$ in weight. He had ten hypnotherapy sessions in all and, at completion, the snoring was eliminated altogether. When followed up by phone at three and six months the patient said that his improvement had been maintained. Hypnotherapy might be tried as a first-line approach before more invasive procedures are considered.

Tom Kraft

80 Harley Street, London W1 G7L, UK

\section{REFERENCES}

1 Kotecha B, Shneerson JM. Treatment options for snoring and sleep apnoea. J R Soc Med 2003;96:343-4

2 Kraft T. The use of direct suggestion in the successful treatment of a case of snoring. Contemp Hypnosis 2003;20:98-101

\section{Medically unexplained symptoms}

Dr Andrew Skinner (June $2003 J R S M^{1}$ ) laments the disappearance of generalist physicians. I could have done with a generalist, or a one-stop multiprofessional clinic, before my haemochromatosis was eventually diagnosed - by myself at the age of 74 .

Over the past decades I have been referred to a rheumatologist for arthritis, to a cardiologist for heart irregularity, to two endocrinologists for diabetes. None of them, nor several general practitioners, spotted my enlarged liver or considered that haemochromatosis might be the cause of it and the other unexplained symptoms and signs. I myself only suspected the possibility while listening to a radio discussion about haemochromatosis.

Incidentally, some $1 \%$ of the population of Ireland are affected by this 'Celtic disease'. Most of them are not aware of it. Neither, presumably, are the several million Irish living in Britain.

\section{David Sowby}

39 Knocksinna Crescent, Dublin 18, Ireland

E-mail: dsowby@gofree.indigo.ie

\section{REFERENCE}

1 Skinner A. Medically unexplained symptoms. J R Soc Med 2003;96:268 


\section{Use of section 5(2) of the Mental Health Act on a medical admissions unit}

A survey by Jackson and Warner ${ }^{1}$ pointed to large deficiencies in doctors' knowledge about consent. Ignorance of the law on capacity to consent to medical treatment could result in inappropriate use of the Mental Health Act (1983). We have audited the use of the Mental Health Act on a medical admissions unit. The unit admits patients with a wide range of acute medical conditions including patients requiring medical management of drug overdose or alcohol withdrawal. It treats more patients with delirium and acute psychiatric problems than most other medical wards.

We reviewed the hospital notes of 14 inpatients detained under the Mental Health Act after discharge from the medical admissions unit. The original reasons for admission were overdose (10), alcohol withdrawal (3) and collapse probably due to a seizure caused by alcohol withdrawal (1).

5 patients were detained by their responsible consultant. Junior staff detained 4 patients after discussion with the responsible consultant; but 5 , in contravention of the Mental Health Act, were detained by junior staff without any evidence of consultation with the responsible consultant. In 12 patients' notes the fact that the patient was unwilling to remain in hospital voluntarily was documented. In all cases the two consultants reviewing notes felt that the decision to detain under 5(2) was appropriate. Overall the documentation of the sequence of events which led to the section, the decision-making process and the mental state of the patient was poor.

The Mental Health Act is an important piece of legislation used frequently in the general hospital. Its misuse could have important medicolegal consequences for affected patients, the doctors involved and their employers. Medical staff working in inpatient specialties need to make sure their knowledge of the Act and the Code of Practice ${ }^{2}$ are up to date.

\section{R Hardern, D Protheroe ${ }^{1}$}

Medical Admissions Unit and ${ }^{1}$ Liaison Psychiatry, General Infirmary at Leeds, UK Correspondence to: R Hardern, Accident \& Emergency, University Hospital of North Durham, Durham DH1 5TW, UK

E-mail richard.hardern@ndhont.northy.nhs.uk

\section{REFERENCES}

1 Jackson E, Warner J. How much do doctors know about consent and capacity? J R Soc Med 2002;95:601-3

2 Code of Practice [http://www.doh.gov.uk/pub/docs/doh/mhcop. pdf], accessed 19 June 2003

\section{Skeletal tuberculosis}

Dr Davies (June 2003 JRSM $^{1}$ ) highlights the challenge faced tuberculosis (TB). We feel that skeletal TB has likewise suffered neglect. Notified cases of non-pulmonary TB have risen by over $25 \%$ in the UK since $1993 .^{2}$ Skeletal TB occurs in approximately $1-2 \%$ of cases of TB. ${ }^{3}$

In the past 18 months our orthopaedics department has treated 22 patients with TB involving bone. Of these, 15 $(68 \%)$ were spinal infections. In addition, we have encountered tuberculous arthritis and osteomyelitis. The time to diagnosis from onset of symptoms ranged from 1 week to 2 years (median 2 months). All but one of the cases arose in patients from ethnic minority groups, most of whom were immigrants or refugees. This concurs with the study of Hayes et al., who found that $95 \%$ of cases of spinal TB occurred in the immigrant population. ${ }^{4}$

In 1968 Walker highlighted the importance of entertaining the diagnosis of $\mathrm{TB}$ as a cause of skeletal pain. ${ }^{5}$ With a rising incidence of all forms of $\mathrm{TB}$, all clinicians should be alert to the possibility of skeletal TB if adverse outcomes are to be avoided.

\section{Sidath H Liyanage}

E-mail sidliyanage@yahoo.com

\section{Chinmay M Gupte}

E-mail chimgup@hotmail.com

\section{Alistair R M Cobb}

E-mail alicobb@yahoo.com

Department of Orthopaedics, Ealing Hospital, Southall, UB1 3HW, UK

\section{REFERENCES}

1 Davies PDO. The challenge of tuberculosis. J R Soc Med 2003;96:262-5

2 [http://phls.org.uk/topics_az/tb/TB_tables_figures/ Nots\%20pulmonary.htm], accessed 14 July 2003

3 Davidson PT, Horowitz J. Skeletal tuberculosis. Am J Med 1970;48: 77-84

4 Hayes AJ, Choksey M, Barnes N, Sparrow OCE. Spinal tuberculosis in developed countries: difficulties in diagnosis. $J R$ Coll Surg Edinb 1996;41:192-6

5 Walker GH. Failure of early recognition of skeletal tuberculosis. BMJ 1968;i:682-3

\section{Rembrandt's left ear}

I suspect that the lesion discussed by Mr Cohen (June 2003 $J R S M^{1}$ ) is a keloid, a not uncommon complication following piercing of the lobe to accommodate an ear-ring. The other diagnostic possibilities that he mentions are more remote.

\section{Giulio J D'Angio}

University of Pennsylvania Medical Center, 2 Donner, 3400 Spruce Street, Philadelphia, PA 19104-4283, USA

\section{REFERENCE}

1 Cohen B. A tale of two ears. J R Soc Med 2003;96:305-6 